This article was downloaded by: [Lancaster University Library]

On: 18 April 2013, At: 07:55

Publisher: Routledge

Informa Ltd Registered in England and Wales Registered Number: 1072954 Registered

office: Mortimer House, 37-41 Mortimer Street, London W1T 3J H, UK

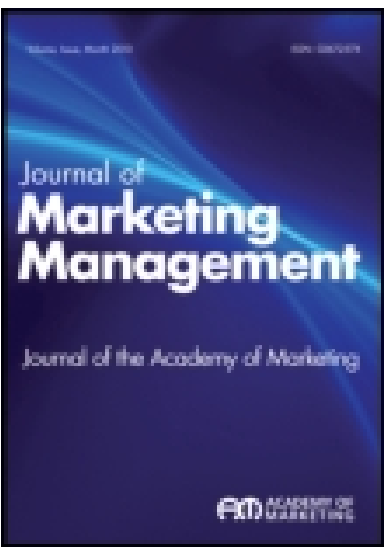
J ournal of Marketing Management
Publication details, including instructions for authors and subscription information:
http:// www.tandfonline.com/loi/ rjmm20

\title{
Towards a richer understanding of consumers in social marketing contexts: Revisiting the stage of change model
}

\author{
Liz Logie-Maclver $^{a} \&$ Maria G. Piacentini ${ }^{b}$ \\ ${ }^{a}$ Edinburgh Napier University, UK \\ b Lancaster University Management School, UK \\ Version of record first published: 09 Sep 2010.
}

To cite this article: Liz Logie-Maclver \& Maria G. Piacentini (2010): Towards a richer understanding of consumers in social marketing contexts: Revisiting the stage of change model, J ournal of Marketing Management, 27:1-2, 60-76

To link to this article: http:// dx.doi.org/ 10.1080/02672571003676429

\section{PLEASE SCROLL DOWN FOR ARTICLE}

Full terms and conditions of use: http://www.tandfonline.com/page/terms-andconditions

This article may be used for research, teaching, and private study purposes. Any substantial or systematic reproduction, redistribution, reselling, loan, sub-licensing, systematic supply, or distribution in any form to anyone is expressly forbidden.

The publisher does not give any warranty express or implied or make any representation that the contents will be complete or accurate or up to date. The accuracy of any instructions, formulae, and drug doses should be independently verified with primary sources. The publisher shall not be liable for any loss, actions, claims, proceedings, demand, or costs or damages whatsoever or howsoever caused arising directly or indirectly in connection with or arising out of the use of this material. 


\title{
Towards a richer understanding of consumers in social marketing contexts: Revisiting the stage of change model
}

\author{
Liz Logie-Maclver, Edinburgh Napier University, UK \\ Maria G. Piacentini, Lancaster University Management School, UK
}

\begin{abstract}
In this paper, we present data from an 18-month-long longitudinal study of a sample of 40 people who received a test for cancer and who were subsequently advised by health professionals on the dietary changes that would lead to improved health. This study investigates the ways that behaviour change is instigated (or not) and how people cope with these changes. We use the Stages of Change model to categorise people by their dominant behavioural response to the test (maintainers, recyclers, no change). From these categorisations, we develop an in-depth understanding of the experience of their behavioural response. By looking at the three possible behavioural responses in this way, we provide insights into the different cognitive, emotional, and behavioural response to the disease trigger. We evaluate the implications for social marketing theory and public policy makers.
\end{abstract}

Keywords consumer behaviour; behavioural change; social marketing

\section{Introduction}

Many social marketing studies are concerned with encouraging the adoption of health behaviours (Andreasen, 2006), such as eating healthier food (McDermott, Stead, \& Hastings, 2005), stopping smoking (O’Connell, Hosein, Schwartz, \& Leibowitz, 2007), taking more exercise (Kiviniemi, Voss-Humke, \& Seifert, 2007), and reducing alcohol or drug consumption (Hastings, Anderson, Cooke, \& Gordon, 2005). A key aspect of public policy in this area is that people not only make changes to their behaviour, but also that they are able to sustain these changes to achieve the desired health benefits (Andreasen, 2006; Hastings \& Donovan, 2002; Peattie \& Peattie, 2003). Previous research in social marketing has explored how people implement behaviour change, but there has been less emphasis on how they cope with the cognitive and emotional aspects of making and maintaining change (Nieuwenhuijsen, Zemper, Miner, \& Epstein, 2006; Rothman, 2000), which is the focus of this paper. Specifically, this research focuses on people who received a test for cancer and who were then advised by health professionals on the dietary changes that would lead to improved health. Their endeavours to make dietary changes are the 
focus of this study, and it is the cancer test and subsequent health advice that are conceptualised as the triggers for behavioural change. This research categorises people by their dominant behavioural response to the test (maintainers, recyclers, no change), investigating the ways that behaviour change is instigated and how people cope with these changes. While not a formal social marketing intervention, the experience of trying to adopt a healthy diet triggered by the test is a useful window through which to explore the emotional and cognitive responses to the disease and the issues around making and sustaining behaviour change. Diet is a challenging area for behaviouralchange interventions for a number of reasons, including the complex interaction of biological, psychological, and social factors influencing behaviour (Bray, McCartney, Dunbar, \& Thoulass, 2009), and also the powerful environmental stimuli that often overwhelm compelling dietary messages (Hill \& Peters, 1998).

\section{Theoretical foundations}

Consumption behaviour associated with personal and social welfare is often of high personal importance to individuals, and, as a result, behavioural changes involve relatively complex processes (Blackwell, Miniard, \& Engel, 2001). One model that has been widely used as a framework for understanding how to achieve changes in behaviour in social marketing contexts is Prochaska and Di Clemente's (1982) Stages of Change model. Prochaska and Di Clemente described five stages of behaviour change (Maibach \& Cotton, 1995), and these have been used by social marketers to understand difficult and time-consuming decisions such as dietary behaviour change (Kotler \& Andreasen, 1987). Andreasen (2006) provides a very useful overview of the model. In summary, the first two stages of the model (pre-contemplation and contemplation) relate to pre-change behaviour; Andreasen (2006, p. 100) combines the third stage (preparation), relating to planning for change, and the fourth stage (action), where behaviour change strategies are put into place; and the final stage is concerned with post-change stages (maintenance, relapse, and recycle, where the person goes through the behaviour-change cycle again to try and achieve success). Critical reviews of the Stages of Change model depict the model as being descriptive rather than being explanatory (Bunton, Baldwin, \& Flynn, 1999). Some have argued that the Stages of Change approach is a valuable tool to categorise stages of behavioural change (Curry, Kristal, \& Bowen, 1992), but it must be used with cognitive and motivational psychosocial processes in order to understand the experience of behaviour change more fully (Bagozzi \& Warshaw, 1990). The following factors have been identified as important for making and sustaining behavioural change: appraisalmaking and behavioural plans (Marlatt \& Gordon, 1985), perceived self-efficacy (Glanz et al., 1994; Schwarzer, 1992), prior experiences and behaviour (Rothman, 2000), and previous successful behavioural modification attempts (Bagozzi \& Warshaw, 1990). Key factors affecting sustained behavioural change relate to the assessment or appraisal an individual makes in relation to the behavioural-change situation they face, their feelings of mastery or control over the situation, and their perceptions of their previous experiences and behaviours in the domain. While the Stages of Change model is useful to broadly categorise the process of change, more indepth understanding about these factors is offered by exploring the ways that people deal with the change, and Coping Theory (Lazarus, 1991) offers a useful framework that encompasses the emotional and cognitive factors that may influence behaviour change. 
Lazarus (1991) defines coping as the processes and strategies that people deploy to help them deal with stressful situations. As with other models of behaviour change, within Coping Theory there is an initial stage whereby the person stops and takes stock of their situation (Bagozzi, 1992; Lazarus, 1991). There are two appraisal processes: primary appraisal, comprising an evaluation of goal relevance, goal congruence, and ego involvement; and secondary appraisal, which includes attribution (external or internal), coping potential, and future expectancy (Lazarus, 1991, pp. 149-150). The appraisal processes are where the person reflects on the behaviour change and makes an assessment of the extent to which the change is desirable and relevant to them, the consequences, and the extent to which they are able to make the change. Although the components of the appraisal processes overlap with the decisional balances and self-efficacy constructs included in the Stage of Change model (Prochaska \& DiClemente, 1992), the appraisal of a threat - and decisions about behaviour change can be seen as a threat in this context - is a function of the environmental (including social) conditions facing that particular person with particular characteristics (Folkman, Lazarus, Dunkel-Schetter, DeLongis, \& Gruen, 1986). Therefore, appraisal refers to the response of the person at a specific time in their particular social and cultural environment, and adds depth to our understanding of the coping responses of individuals.

The coping responses of individuals mainly serve three functions: (1) problemfocused function, where changes are made to the person's problem environment to alleviate stress, such as planful problem solving, confronting the situation, and accepting responsibility; (2) emotion-focused function, which involves managing emotional aspects of situations, such as by denying a threat exists, by distancing oneself from the threat or avoiding thinking about the stressful situation (Folkman \& Lazarus, 1980); and (3) cultivating, seeking, and using social support (offering emotional, tangible, or informational support), most often from family, friends, or work colleagues (Folkman \& Lazarus, 1988; Pearlin, 1989).

In the current study, the participants are coping with the potential stress associated with the initial test for cancer, but are then subsequently coping with the challenges and difficulties associated with the dietary change for better health. How the participants coped with the results impacts on their approach to implementation of changing behaviour (Folkman et al., 1986) and how they perceive the challenges associated with dietary change.

This paper approaches the topic of behaviour change differently from other studies. Starting with the data, we use the Stage of Change model to categorise people by their dominant behavioural response to the test (change and maintain change, relapse and recycle, limited or no change). From these categorisations, we develop an in-depth understanding of the experience of their behavioural response, in particular exploring coping responses. By looking at the three possible responses in this way, we hope to illuminate and develop understanding of sustained behavioural change.

\section{Methodology}

This was a longitudinal qualitative study over an 18-month period of 40 people, all living in Central Scotland. All participants were recruited via a hospital consultant (Lothian University Hospitals NHS Trust, Royal Infirmary of Edinburgh), and full 
ethical approval and permission for the research interviews was granted by the Medicine/Clinical Oncology Research Ethics Committee.

The sample comprised people who had received a diagnostic test for (colorectal) cancer, the result of which demonstrated that they did not have cancer but were suffering from a minor bowel disease. Following this diagnosis, participants received advice to make dietary changes to manage the symptoms of the disease. The diagnostic test and subsequent dietary advice together represent a health-related intervention that is the external stimulus that triggered behavioural change in this context.

The main form of data collection was in-depth interviews, using a broad conceptual framework developed from the literature (Miles \& Huberman, 1994). Each participant was interviewed on an individual basis three times over the 18 -month study period, and the interviews took place every six months. The purpose of the interviews was to explore the ways that people made changes to their behaviour in response to an external stimulus (in this case, the test for cancer and subsequent knowledge of their minor bowel illness) and the ways that behaviour changes are implemented and sustained. Both the social context of the stimulus and the strategies for behaviour change were explored to clarify why people change within a given set of circumstances. Data analysis was undertaken using content analysis and holistic interpretation of the data (Bryman \& Burgess, 1994). In addition, we recorded their stage of change at each meeting, using a staging algorithm (Curry et al., 1992), and these data were used as a basis for tracking their behaviour.

The age range for participants was 30-83 years of age, and the mean age was 51 years. There was an even mix of gender and socio-economic status (as assessed by the deprivation categories [McLoone, 1991], and classified as high socio-economic status [HSE]; medium socio-economic status [MSE]; and kow socio-economic status [LSE]). A description of the sample is provided in Table 1.

A total of 12 participants were classified as maintainers (eight males, four females); the age range was 51-83 (mean age 62) and 11 lived with their spouse or partner. The participants in this group had made changes to their diet at the onset of the bowel disease (up to six months before the test) or just after receiving the result of the test, and they were all in the 'action' or 'maintenance' stage of change throughout the study period. Some of these participants were in 'maintenance' at the start of the research, which is explained by changes they made to their diet when the symptoms of bowel disease first arose, which for some was up to six months before the test.

A total of 15 participants were classified as relapsers (eight males, seven females); the age range was 35-78 (mean age 54) and nine lived with their spouse or partner. These participants relapsed from change when they experienced stressful events in the workplace or did not receive continuous support from partners or family members.

A total of 13 participants were classified as demonstrating limited or no change (eight males, five females); the age range was 33-80 (mean age 62) and 11 lived with their spouse or partner. The term 'limited change' acknowledges the actions undertaken (especially in Stage of Change terms), but recognises that the changes were limited in that they were driven more by weight-loss goals than by longer-term health concerns.

\section{Analysis/findings}

The analysis section deals with each group in turn, providing insights into the different cognitive and emotional responses. 


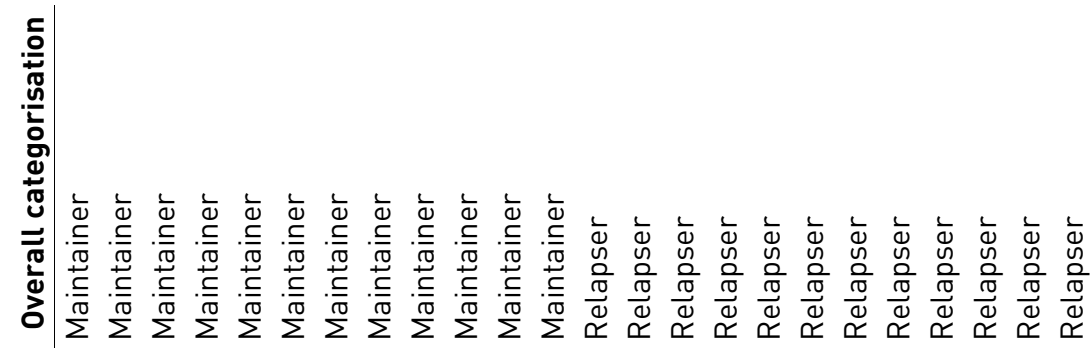

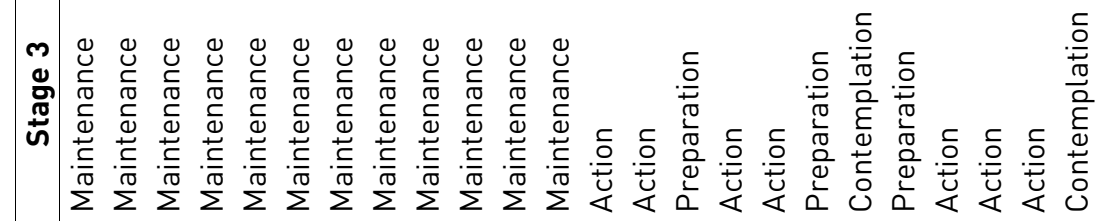

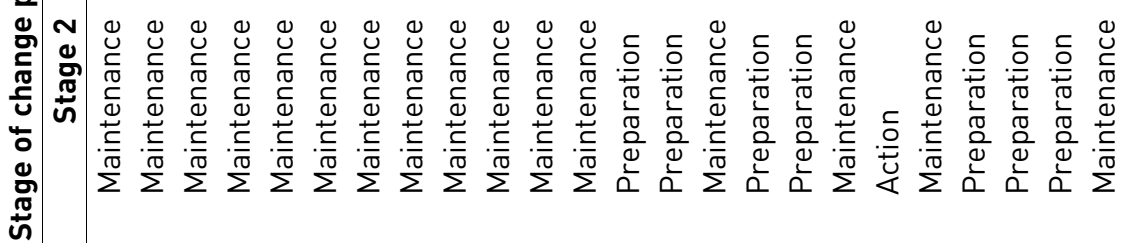

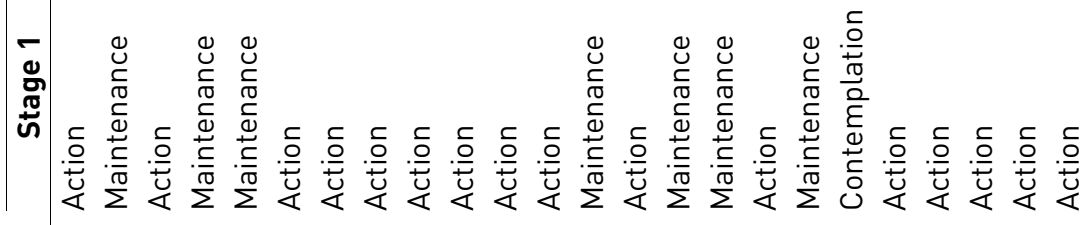

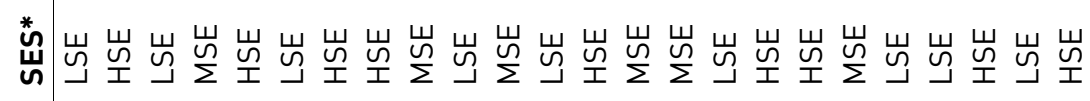

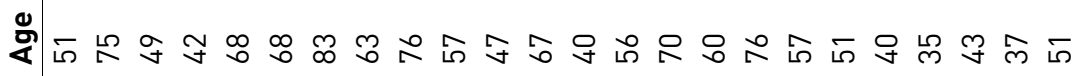

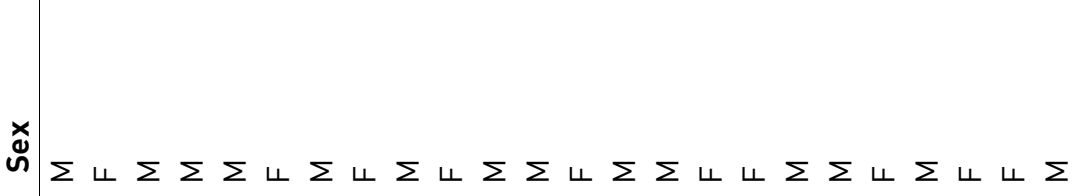

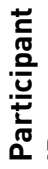

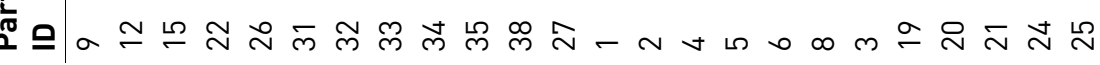




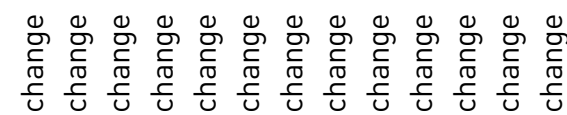

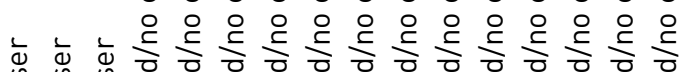
心

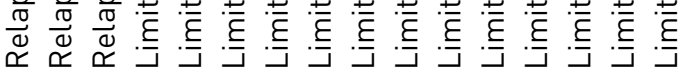
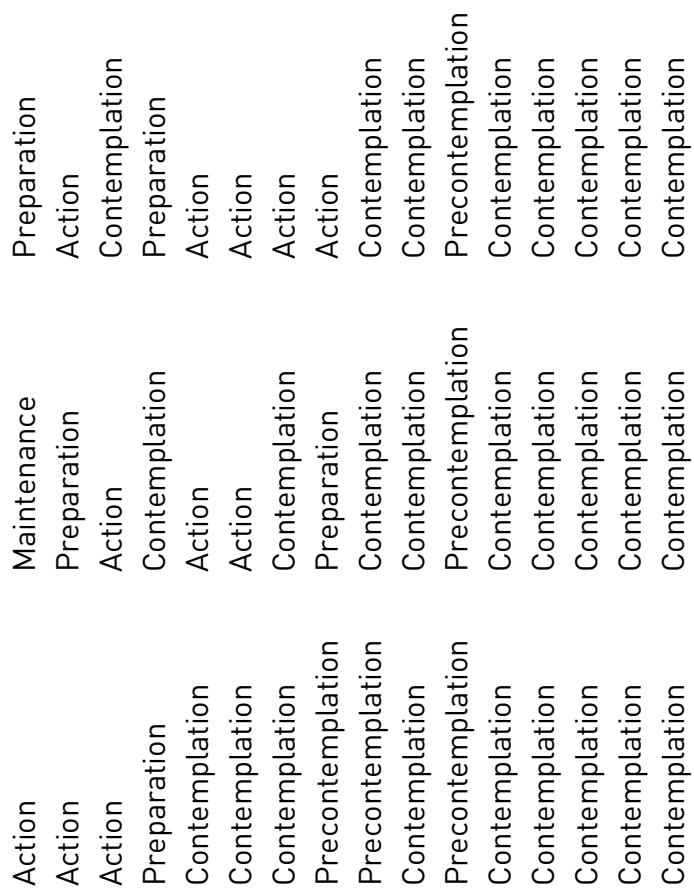

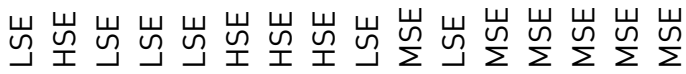

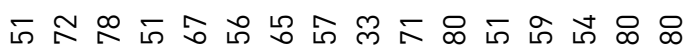

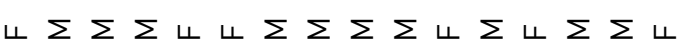

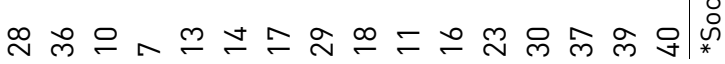




\section{Group 1: Maintainers}

Maintainers were characterised by a distinct drive towards behavioural change, comprising a commitment to change and a strong self-belief in their ability to make the change. This excerpt is typical of those maintaining behavioural change:

I stopped eating curries. I often walk past curry houses and I have to take a deep breath and walk past. I have strong willpower. I have kept my drinking low and drink fresh orange only. (Participant 9, male, 51y)

For many maintainers, a dominant theme related to self-control or willpower, and this was commonly perceived as a resource that could be drawn on to effect change. Maintainers also had a tendency towards self-reflection, taking a critical perspective on their own past behaviour. For example, some were able to recognise problems with their previous dietary behaviour, such as not eating breakfast.

[In the past] I didn't have breakfast at all. When I got up, I didn't want breakfast. But I did have a good idea about diet really ... [Now] I eat breakfast and have introduced brown bread, vegetables and pasta ... It has helped me with my symptoms now. (Participant 27, male, 67y)

A common perception among this group, hinted at in this excerpt, related to the fairly high levels of general and specific knowledge about the relationship between diet and health. This appeared to contribute to the self-confidence held among this group, since they were starting from a good knowledge base (even if good eating practices had not been in place).

The maintainers provided examples of a range of problem-based coping strategies to alleviate the source of distress, and their strategies were typically explained in great detail and described at the level of everyday survival with this disease. The overall effect was that diet played a very important and immediate role in their lives and that they took very seriously the connection between diet and immediate health effects. For example, participants described how they ate specific foods on a daily basis to discourage the symptoms of their bowel disease and the discomfort they had experienced. One participant described her history and experience of the symptoms of bowel disease, and explained how she had constructed a list of specific foods that she could not enjoy with the disease and eliminated them from her diet.

I just stay on the brown bread, high bran, Weetabix, fruit and vegetables. I remember which foods from experience. If I have been out to a restaurant and I have had quite a full meal, it is an hour or two later that it starts griping. (Participant 12, female, 75y)

This example of planful problem solving to cope with this problem demonstrates how she had taken active steps to adjust her diet to alleviate the physical symptoms that were involved with bowel disease. The participants recognised that coping strategies, such as planful problem solving, required effort and commitment and was an on-going process.

The strategy of accepting responsibility was important, where the participants reflected on and accepted their own responsibility and role in effectively making the necessary changes for improved health. For example, participants realised that their low self-worth contributed to their bouts of eating or drinking the 'wrong' foods: 
I have always had low self-confidence but this [new healthy-eating programme] has made me feel better about myself and my wife can see the changes in me. I didn't like myself before and I was on a destruct programme of eating and drinking too much. (Participant 9, male, 51y)

Accepting responsibility was an important strategy for maintainers, but the support in making dietary changes they received from their social network, and in particular their significant others, was perceived to be a major factor in maintaining change.

My wife doesn't always eat the same diet as me but is very supportive of me and we never have a fry up. My son is also supportive and has a very healthy diet. I am a positive person and nothing really influences me. (Participant 26, male, 68y)

Emotion-focused coping strategies involve keeping emotional reactions under control, and for maintainers the main emotion-focused strategies were self-control and positive reappraisal. Self-control involves regulation of desires and emotions (Folkman et al., 1986), and was demonstrated in the discussions people had around their strategies to stop them engaging in unhealthy behaviour. Participants undertook a variety of pursuits to alleviate feelings of boredom, stress, or loneliness, and these were largely recognised as being substitutes for unhealthy eating behaviour and to distract them from negative emotional states.

I make myself busy. I have been working on my fish pond. I paint quite a lot. I like to do those things when things are getting me down. (Participant 32, male, 83y) I sit and cross stitch, go out in the car for a run. At first when my husband died, I just got out of the house, jump in the car and drive. I'd phone my daughter. Now I have other things such as being an active member of the church and this helps with the diet. (Participant 35, female, 57y)

Positive reappraisal emerged as a key coping strategy in maintaining change, whereby participants reflected on their past successes and achievement in maintaining changes.

I have been keeping positive about the diet and there is no point in straying away from it. I feel so much better when I don't eat lots of red meat. (Participant 12, female, 75yl

The participants recognised and reflected on the perceived health benefits that dietary change provided, most notably as physical discomfort subsided.

The final major theme in relation to the maintainers' coping strategies relates to the role of their social support network. Social support networks were critical for ensuring their successful and enduring change. Peers provided both emotional support (mainly in the form of helping them to communicate their feelings) and practical support, especially as they adopted this new set of behaviours (e.g. cooking, preparing lunches, reminding about diet). Family and peer support groups encouraged maintainers to believe that they could sustain their dietary changes over time, and social support networks appeared to be critical in the development of feelings of self-efficacy and hence self-worth.

\section{Group 2: Relapsers - Some behavioural change, but relapses over time}

Relapsers tended to have low confidence in their health-related knowledge, and typically had a history of poor diet in childhood and early adulthood. It was not that they had no knowledge of health and diet; it was more that they were less practised in 
this area, and therefore had less confidence about how to put their knowledge into practice. Often this was linked to stories where blame for poor dietary habits was attributed to factors external to the individual:

I lived in Surrey but most of my life was in London. I lived on sandwiches and was too tired to make a meal when I got home. I had breakfast provided if I was up on time. Different priorities then - get up and get out. I had a stressful lifestyle. Most of the people I know are aware of how you ought to eat. (Participant 6, female, 76y)

Although this individual accepts some responsibility ('I was too tired'), blame for her poor dietary behaviour is mainly directed at external sources, in this case the pressures of work and the stressful lifestyle she had at that time. This external attribution of responsibility for dietary behaviour leads to a reduced likelihood of feelings of mastery and success in relation to diet, which ultimately undermines the development of self-efficacy in this context.

Perceived failure was a dominant theme among this group, and they differed from the maintainers in the fact that they recognised that relapse was a very real possibility, and they had a less positive perception of their ability (self-efficacy) in maintaining change and achieving success. Their assumptions and expectations around the possibility of failure were a major concern for relapsers, accompanied by a widely acknowledged and discussed anticipation of fear around behavioural change. Relapsers tended to dwell on past behavioural efforts (and failure) and believed that successful behavioural change was beyond them.

Sometimes I have poor willpower and will eat a little bit extra but not often. At times, it is difficult when I try to eat a good diet. I am not an indulgent person but I do like chocolate and ice cream. (Participant 4, male, 70y)

There was a perception among relapsers that they were inadequately equipped to make the necessary changes, and there was a clear tendency to focus on problems/triggers that encroached on their behavioural change success.

I do have binges of chocolate. I have to fight my yen for chocolate. I daren't go near the chocolate. In the last couple of years, I have craved chocolate and can't trust myself with sweets. When I was young, I wanted to keep a reasonable figure. It is important when you are young; I don't care much about that now. Everyone needs a little enjoyment in their lives. In saying that I feel guilty and awful in myself afterwards but I can't help it. I am also fond of white bread and occasionally binge on that instead of sticking to the wholemeal stuff. (Participant 6, female, 76y)

Relapsers made statements about their plans to solve the problems of their dietary behaviour, and in this respect were similar to the maintainers in their use of planful problem solving.

I have been trying to eat more fruit and vegetables because of bowel health; fruit in the morning and I take All Bran. I have been making these changes since May. My wife has gone along with these changes. Our grandchildren come along but I don't eat the pudding any more. (Participant 36, male, 72y).

However, the role of social support appeared to be critical in the success or otherwise of these strategies, and where more disrupted or sporadic social support was in place, the relapsers found it difficult to maintain change. One participant exemplified this, when she described how she did not take responsibility for her own diet when her husband was around. 
My husband is back at work now so I can choose what I want to eat. It was harder at first because he was doing all the cooking. (Participant 28, female, 51y)

The emotion-focused strategy of self-control was important for this group, and all had strategies in place, often linked to other changes they had made in their lives (e.g. changing jobs, joining a gym, starting a new hobby).

I feel positive and proud of myself. I go swimming five times a week. I did have a cappuccino but I said to myself afterwards that I must not slip. I have an addictive personality and it required strong willpower. I have re-evaluated my life and have more self-control. (Participant 1, female, 40y)

These activities appeared to provide the additional benefits of boosting their selfconfidence to maintain their lifestyle and dietary changes. Self-control was a widely adopted coping strategy for all participants making dietary change, but relapsers differed greatly from maintainers in that they struggled to maintain control in social situations. In highly social contexts, in particular, the combination of their lack of selfefficacy (belief in longer-term achievement) and reduced volition (desire to act in the long term) led to relapses in their behaviour.

I have re-evaluated my life because of my illness and have more self-control. But at Christmas, I just wanted to be normal like everyone else and eat meat and drink caffeine products associated with Christmas. (Participant 1, female, 40y)

While relapsers were clearly committed to the goal of eating healthily, this commitment was not as strong as for the maintainers, and hence their greater likelihood of relapse. There was also evidence of escape-avoidance strategies around food, with the social context playing a role. This is illustrated in the following quote from a relapser who gets frustrated at not being able to join friends for coffee.

I love the aroma of coffee and I can't do it. I was fed up of meeting people for coffee and having a glass of water. That was my first relapse in three years. (Participant 1 , female, 40yl

Relapsers did not seem adequately prepared to cope with their emotional responses in relation to dietary change. Their patterns of behaviour change were often in short cycles when they relapsed and returned to action stage or contemplation. Relapsers were very reliant on their social support network, but tended to perceive this more in terms of their formal support networks (such as health professionals offering guidance and advice) than their family and friendship groups. When family were discussed, participants appeared to be dependent on their family to lead and implement the change, and perceived there to be a joint rather than personal responsibility for change. Linked to this, the relapsers appeared less able to communicate their needs to their social support network, despite their great reliance on them.

\section{Group 3: No (limited) change}

This group demonstrated very limited change to their dietary behaviour and attitudes over the study period. An important theme with regard to this group related to their reluctance to accept or reflect on the links between their diet and their health. While these participants claimed to know about eating a healthy diet, they did not seem to accept that their bowel health was at risk by having an unhealthy diet. 
My wife says if she was not here, I would starve. I have no intention of making any changes as I have a fairly good knowledge about what foods are good and what are not. I eat anything and everything and have no disagreement at all. I am not worried about my health at all. (Participant 40, male, 80y)

This participant displayed characteristics of emotion-focused coping (Folkman et al., 1986), distancing himself from the problem, and not accepting responsibility for dietary change. Although his perception was that he had good knowledge levels around diet and health, when he described his dietary behaviour, it was clear he had made very limited dietary changes, mainly due to the pressure from his wife and her understanding of the links between diet and health. Further, like other participants, this participant seemed resistant to change, not accepting the need for change. Age was not a factor in this non-acceptance but more the limited understanding of the link between bowel health and diet. For example, one participant did not listen to his consultant and did not accept that there were real risks involved with the illness that were within his control; rather, he distanced himself from the problem by focusing on future rather than current effects.

The nurses and doctors told me I will have a colostomy bag when I am older. Yes but I don't think about being old. I can't imagine being old. I am young. She has been putting more veggies on my plate but I am not a veggie person. (Participant 18, male, 33y)

Although some of the participants were aware of the long-term risks of serious illness if they did not change their diet, many participants continued to eat an unhealthy diet mainly because they did not recognise the link between the information given to them and the longer-term risk of health. The majority of these participants had little specific knowledge of diet in terms of what was at stake with their bowel health and had little experience of eating a healthy diet.

In the discussions around dietary behaviour, this group generally displayed patterns of poor dietary behaviour, poorly planned, and seemingly beyond their control. In their reflections about behavioural change for health, there was a tendency to equate the impact dietary changes have on health with weight loss only.

They never told me to change my diet. I realise I need to lose weight. I never thought about the risks. (Participant 23, male, 51y)

For this group, there were some examples of coping strategies in place, but they served a different purpose than for maintainers or relapsers. Rather than having strategies in place to help them make and maintain behavioural change, these strategies were really to help them manage their very limited (or no) change in response to the test. These people are dealing with the consequences of this decision, in terms of physical (i.e. continued ill health and occurrence of the symptoms), psychological (e.g. low self-esteem, self-efficacy), and social (pressure from family, peers) consequences.

The first point to note about this group is that the extent to which they made any efforts to change behaviour was directly related to the extent to which they felt the physical symptoms of their bowel disease (e.g. pain, discomfort). In the absence of an immediate reminder of the need for change (knowledge of bowel health and diet), no changes were made or considered. Related to this was evidence of denial strategies, a non-acceptance of the situation they faced. There was also some (limited) evidence of resistance strategies, where the participants resisted change in a rather fatalistic way ('I'll go out as I came into this world'). When members of this group did talk about 
their pain and discomfort, they talked in a disheartened way, resigned to the pain and the lack of power they had over it. There was a perceived inability to affect it in any way through dietary change. This is related to escape/avoidance strategy, whereby they believe that medication will sort things out. Also, there appeared to be limited ability to take control/accept responsibility for the problem, which is the opposite of the problem-focused strategy of 'accepting responsibility'. Female participants who were gatekeepers in their family did not want to change the routine:

They recommended high fibre but my husband doesn't like brown bread so we don't buy it. I think I am eating a good diet but my husband objects because he has nothing wrong with his bowels. (Participant 11, female, 71y)

They were reliant on others, but this is not 'seeking social support' as a coping strategy. Rather, it is a either a passive reliance on others to feed them, and the extent to which they are fed a bowel-healthy diet is contingent upon the extent to which the other person is committed to dietary change or they are prepared to sacrifice their health for the sake of keeping things they way they always were.

Among the no-change group, the social support network was barely mentioned. Members of this group tended not to take any support offered by family (partner) because they were in denial (distancing) about the need for change. When they did seek out social support, it was notably absent. The characteristic non-communication with friends/peers about the required changes in behaviour (unsurprising, given their reluctance to accept the changes) resulted in a situation where their situational contexts (relating to socialising) did not change. Typically, members of this group continued their lives with the same friends, doing the same things, eating the same foods, and drinking the same drinks.

Although there were no clear patterns between age and effort to change, it is worth noting that there are four people who are at least 80 years old in the study, and the three of them fell into the no-change category. Perhaps for those three, there was a view that behaviour change was not really worth the effort

\section{Discussion}

In this study, we have investigated the way that people cope with making and sustaining behaviour change in relation to bowel health. Adopting an in-depth longitudinal approach, this paper has categorised people by their dominant behavioural response to the initial trigger of change (change and maintain change, relapse and recycle limited or no change), and then explored the ways that people cope with making and maintaining behavioural change.

The way that people respond to the initial disease test, and hence the extent to which this is a trigger of change, relates to three main factors: (1) knowledge about the relationship between diet and bowel health; (2) perceptions of the consequences of any attempts of change or taking responsibility for change; and (3) the presence and nature of social support networks, especially partners. When there was solid understanding of the links between diet and bowel health, when the consequences of behaviour change were clear and convincing, and when there were good social support networks in place for the participant, then a change in behaviour was more likely to be maintained. Maintainers possessed good knowledge and understanding of the links between diet and bowel health, and were very focused on the health consequences of their behaviour change. This compares with the relapsers, who tended to have 
inconsistent or incomplete knowledge about the links between diet and health, and the non-changers, who possessed very limited knowledge about the links between diet and bowel health, and thus did not discuss any consequences of behavioural change (since they did not appreciate or know of any reason for change). Effective maintainers also had high expectations about the support they would receive from their social support network, and placed great importance on this support. In contrast, the relapsers and non-changers tended to have limited social support for change in this domain. This is not to say that that did not have a network; rather, they did not perceive the social support network to have a role to play in their dietary behaviour. Where some or all of these factors were eroded, then there was less likelihood of effective behaviour change occurring or being maintained.

Clearly, a functional knowledge of diet is required in order to instigate change in the first place (Huffman \& Houston, 1993; Huffman, Ratneshwar, \& Mick, 2000), and it appears that this must be linked to the consequences of change in order to have an effect. The participants who were maintainers in this research acquired knowledge concerning diet through socialisation and made the link between diet learned in childhood and health (Ward, 1974). The important point is that the dietary knowledge needed to be specific to the illness; in this case, bowel disease and the knowledge had to be adapted to such individual tolerances of different foods (Burden, 2001). This study found that this knowledge of diet led to long-term goal-directed behaviour and is a key factor in dietary change and maintenance of change (Huffman et al., 2000). Only those participants who had this prior knowledge of appropriate diet set longer-term goals for the maintenance of change (Huffman et al., 2000).

Participants' attitudinal responses to the trigger of change (i.e. the test) may well have influenced how they responded in behavioural terms. Some participants clearly exhibited optimistic outlooks on life, which likely influenced their perceived selfefficacy, while others had a more pessimistic (often fatalistic) approach to their illness. This emerged in the comments from participants, and most influenced their perceptions about the consequences for change, which in turn influenced their efforts to make dietary changes.

In terms of how people coped with their attempts at change, there were clear differences between the maintainers and relapsers. Maintainers typically deployed the full range of coping strategies, effectively utilising: problem-focused strategies (such as positive reappraisal and planning) to manage the daily challenges they faced; emotionfocused strategies, in particular practising self-control; and making consistent and extensive use of their social support networks to help and support them in their attempts at dietary change. This contrasts with the relapsers, who also reflected on their past behaviour but focused on their failed attempts at behavioural change and were lacking in confidence in their ability to effect change (i.e. possessed low self-belief in this regard). This group adopted mainly emotion-focused coping strategies (such as escape-avoidance) and were particularly concerned with issues around self-control in social situations. For relapsers, a key concern was the ability to practice self-control around food when in social situations. But, ironically, this group had fairly limited social support networks, and hence fewer opportunities to practice self-control in public/social situations, so the cycle was difficult to break. There were some examples of planful problem-solving provided, but these tended to be fairly limited, and helped in the short-term only. For relapsers, emotion-focused strategies predominated. The limited or no-change group found change too difficult and beyond their control, and generally were unconvinced of any need for change, so therefore did not employ any coping strategies (since they were not making behavioural change efforts). 
The important factors in terms of dietary change and maintenance of change were found to be the individual's social context and the environmental influences that impacted on them making and maintaining change (Daley \& Zuckoff, 1999). Interestingly, there did not appear to be any effect of social class on the ways that people made change in this context. Rather, the ways that social support was drawn on were important for understanding the maintenance of change (Crockett, Grier, \& Williams, 2003; Folkman et al., 1986). The role of committed social networks to supporting the behaviour change appears to be a critical factor in the success of the maintainers, and the challenge for social and public policy in this domain is how to convince, encourage, and develop that support for all those making major dietary changes. This focus on social context makes a strong contribution to the new critical thinking in social marketing concerning methodological approaches that concern understanding long-term relationships in behaviour-change strategies (Hastings \& Saren, 2003).

The limitations of our study are that the research was carried out in one site within Scotland where there are major issues with unhealthy dietary behaviours leading to diseases such as minor bowel illness and colorectal cancer. The problems faced by people in Scotland with poor diet may vary from country to country, but the issue concerning maintenance of dietary change is transferable to other countries, and it is recommended that this research may be replicated in other countries. Another possible limitation is that the study did not include members of the participants' social support network, and this could form a useful focus in further work in this area to provide a richer picture of the deeper issues. Finally, although a longitudinal approach was adopted over a significant period of time (18 months), some follow-up work with the same participants would provide further evidence and insights into the issues around making and maintaining behavioural change.

\section{Implications for social marketing management}

This paper focused on the individuals who made and maintained behaviour changes after a trigger of illness. This approach is known as a downstream application within social marketing (Andreasen, 2006, p. 6), and such understanding is critical for informing social marketing campaigns (more upstream approach) to improve bowel diet and health. Better education, interaction, involvement, and understanding are required to develop effective campaigns for tackling health (Peattie \& Peattie, 2003).

Knowledge of the link between diet and illness is an area where an upstream approach through community exercises, communicating more knowledge to families, would be beneficial (Huffman \& Houston, 1993). Mass marketing advertising will raise awareness, but more interactive social marketing work is required in terms direct marketing campaigns, such as public-relations events linked to healthy products such as Kellogg's Bran Flakes or 5 A Day recommended products. Leaflet drops/Internet sites concerning messages and education about bowel health and diet are essential both in communities and within hospitals, schools, and GP practices. More courses concerning healthy nutrition and its links to illness should be compulsory as part of the medical and nursing curriculum, as there was little evidence of consistent standards of dietary knowledge, especially concerning bowel diet amongst health professionals. The implications from this new educational approach would be that a member from the patient's social support network (partner, family member, or close friend) should 
be encouraged to accompany the individual to hospital appointments where dietary advice is given out initially so that they can take part in the planning for dietary change.

\section{Acknowledgements}

The authors would like to thank all the participants who took part in this study and The Lothian University Hospitals NHS Trust, Royal Infirmary of Edinburgh, for its cooperation and assistance with this project.

\section{References}

Andreasen, A.R. (2006). Social marketing in the 21st century. London: Sage.

Bagozzi, R.P. (1992). The self-regulation of attitudes, intentions and behaviour. Social Psychology Quarterly, 55(2), 178-204.

Bagozzi, R.P., \& Warshaw, P.R. (1990). Trying to consume. Journal of Consumer Research, 17, 127-140.

Blackwell, R.D., Miniard, P.W., \& Engel, J.F. (2001). Consumer behaviour (9th ed.). Orlando, FL: Harcourt.

Bray, J.K., McCartney, G., Dunbar, J.K., \& Thoulass, J. (2009). Health behaviour change: Do we know what works and is this being implemented in Scotland? Symposium Report, Royal College of Physicians of Edinburgh, Scotland. Retrieved from

Bryman, A., \& Burgess, R.G. (1994). Analyzing qualitative data. London: Routledge.

Bunton, R., Baldwin, S., \& Flynn, D. (1999). The stages of change model and its use in health promotion: A critical review. Centre for Social and Policy Research, University of Teeside, UK (reviewed by Health Scotland).

Burden, S. (2001). Dietary treatment of irritable bowel syndrome: Current evidence and guidelines for future practice. Journal of Human Dietetics, 14(3), 231-241.

Crockett, D., Grier, S., \& Williams, J.A. (2003). Coping with marketplace discrimination: An exploration of the experiences of black men. Academy of Marketing Science Review, 4, 1-18.

Curry, S.J., Kristal, A.R., \& Bowen, D.J. (1992). Application of the stage model of behaviour change and dietary fat reduction. Health Education Research, 7, 97-105.

Daley, D., \& Zuckoff, A. (1999). Improving treatment compliance. Center City, MN: Hazelden.

Folkman, S., \& Lazarus, R.S. (1980). An analysis of coping in a middle aged community sample. Journal of Health and Social Behavior, 21, 219-239.

Folkman, S., \& Lazarus, R. (1988). Coping as a mediator of emotion. Journal of Personality and Social Psychology, 54(3), 466-475.

Folkman, S., Lazarus, R.S., Dunkel-Schetter, C., DeLongis, A., \& Gruen, R.J. (1986). Dynamics of a stressful encounter: Cognitive appraisal, coping and encounter outcomes. Journal of Personality and Social Psychology, 50(5), 992-1003.

Glanz, K., Patterson, R.E., Kristal, A.R., Di Clemente, C.C., Heimendinger, J., Linnan, L., \& McLerran, D.F. (1994). Stages of change in adopting healthy diets: Fat fiber and correlates of nutrient intake. Health Education Quarterly, 21(4), 499-519.

Hastings, G., \& Donovan, R.J. (2002). International initiatives: Introduction and overview. Social Marketing Quarterly, 8(1), 2-4.

Hastings, G., \& Saren, M. (2003). The critical contribution of social marketing. Marketing Theory, 3(3), 305-322.

Hastings, G., Anderson, S., Cooke, E., \& Gordon, R. (2005). Alcohol, marketing and young people's drinking: A review of the research. Journal of Public Health Policy, 26, 296-311.

Hill, J.H., \& Peters, J.C. (1998). Environmental contributions to the obesity epidemic. Science, 280(5368): 1371-1374. Retrieved July 19, 2009, from http://www.rcpe.ac.uk/journal/ abstracts/health-behaviour-change/Bray_et_al.pdf 
Huffman, C., \& Houston, M. (1993). Goal orientated experiences and the development of knowledge. Journal of Consumer Research, 20, 190-206.

Huffman, C., Ratneshwar, S., \& Mick D.G. (2000). The why of consumption: Contemporary perspectives on consumer motives, goals and desires. London: Routledge.

Kiviniemi, M., Voss-Humke, A.M., \& Seifert, A. (2007). How do i feel about the behavior? The interplay of affective associations with behaviors and cognitive beliefs as influences on physical activity behavior. Health Psychology, 26(2), 152-158.

Kotler, P., \& Andreasen, A. (1987). Strategic marketing for non-profit organisations. Upper Saddle River, NJ: Prentice-Hall.

Lazarus, R.S. (1991). Cognition and motivation in emotion. American Psychologist, 46(4), 352-367.

Maibach, E.W., \& Cotton, D. (1995). Moving people to behavior change: A staged social cognitive approach to message design. In E.W. Maibach \& R.L. Parrott (Eds.), Designing health messages. Newbury Park, CA: Sage.

Marlatt, G.A., \& Gordon, J.R. (1985). Relapse prevention: Maintenance strategies in the treatment of addictive behaviours. New York: Guildford Press.

McDermott, L., Stead, M., \& Hastings, G. (2005). What is and what is not social marketing: The challenge of reviewing the evidence [Conference edition]. Journal of Marketing Management, 21(5-6), 545-553.

McLoone, P. (1991). Carstairs scores for Scottish postcode sectors from the 1991 census. Glasgow, Scotland: Public Health Research Unit, University of Glasgow.

Miles M.B., \& Huberman, M. (1994). A qualitative data analysis, An expanded sourcebook (2nd ed.). London: Sage.

Nieuwenhuijsen, E.R., Zemper, E., Miner, K.R., \& Epstein, M. (2006). Health behavior change models and theories: Contributions to rehabilitation. Disability and Rehabilitation, 28(5), $245-256$.

O'Connell, K.A., Hosein, V.L. Schwartz, J.E., \& Leibowitz, R.Q. (2007). How does coping help people resist lapses during smoking cessation? Health Psychology, 26(1), 77-84.

Pearlin, L.I. (1989). The sociological study of stress. Journal of Health and Social Behavior, 30, 241-256.

Peattie, S., \& Peattie, K.J. (2003). Ready to fly solo? Reducing social marketing's dependence on commercial marketing theory. Marketing Theory, 3(3), 365-385.

Prochaska, J.O., \& Di Clemente, C.C. (1982). Transtheoretical therapy: Towards a more integrative model of change. Psychotherapy: Theory, Research and Practice, 20, 161-173.

Prochaska, J.O., \& Di Clemente, C.C. (1992). Stages of change in the modification of problem behaviors. Progress in Behavior Modification, 28, 183-218.

Rothman, A.J. (2000). Towards a theory-based analysis of behavioral maintenance. Health Psychology, 19(Suppl. 9), S64-69.

Schwarzer, R. (1992). Self efficacy in the adoption and maintenance of health behaviours: Theoretical approaches and a new model. In R. Schwarzer (Ed.), Self-efficacy: Thought control of action (pp. 217-242). Washington, DC: Hemisphere.

Ward, S. (1974). Consumer socialisation. Journal of Consumer Research, 1(2), 1-14.

\section{About the author}

Liz Logie-Maclver is a lecturer in consumer behaviour and social marketing at Edinburgh Napier University Business School in Edinburgh, Scotland. She was previously employed in the field of applied social marketing within the health sector in Scotland. She has also been employed within the hospitality and tourism industry. Her PhD concerns the making and maintaining of dietary behaviour change. The focus of this study was minor bowel disease in a study within the Royal Infirmary of Edinburgh. She has published papers in the European Advances in Consumer Research and in the Journal of Marketing Management. 
Corresponding author: Liz Logie-MacIver, School of Marketing, Tourism and Languages, Edinburgh Napier University, Craiglockhart Campus, Edinburgh, EH14 1DJ.

T +441314554419

E1.logie-maciver@napier.ac.uk

Maria Piacentini is senior lecturer in marketing at Lancaster University Management School in the UK. Her research focuses on the consumption behaviour of vulnerable consumers, with specific interest in the coping strategies employed by consumers in difficult situations. She attracts external interest and public policy funding, including the Office of Fair Trading, Greater Glasgow Health Board, and Lanarkshire Health Board, and she has published her work in a number of journals, including the Journal of Business Research, the Journal of Marketing Management, Advances in Consumer Research, the Journal of Consumer Behaviour, International Journal of Non-Profit and Voluntary Sector Marketing, International Review of Retailing, Distribution and Consumer Research, Appetite, and Food Quality and Preference.

T +441524593906

E m.piacentini@lancaster.ac.uk 